\title{
On How and Why Intellectuals Deceive Themselves: A Paul Hollander Retrospective
}

\author{
Alexander Riley ${ }^{1}$ \\ Published online: 18 October 2017 \\ (C) Springer Science+Business Media, LLC 2017
}

\section{One of a Dwindling Breed}

That Paul Hollander is not more widely celebrated by his own discipline is perhaps itself something of a corroboration of the ascendancy of the alienated, adversary intellectual culture that has been the central theme in much of his research. The wide learning, rigorous intellectual spirit, and grand vision evident in that work could once be found with some frequency in American sociology, in the books and articles of men like Robert Merton, Seymour Martin Lipset, Edward Shils, Barrington Moore, and Daniel Bell. Hollander is today one of the rare remaining reminders that a half century or so ago, before the academic revolution that accompanied the broad cultural sea change of the 1960s and 1970s, there existed serious thinkers, brought to the discipline by the desire to understand how human societies really work. These scholars were seemingly immune to the kind of self-righteous ideological and moral prejudices that provide in advance answers to inquiries that should be settled empirically and they were therefore prepared to modify or abandon hypotheses based on evidence. Their acute vision was fortified by long years of study not only in their own fields but also in adjacent disciplines such as history and political science.

Hollander's intellectual trajectory was powerfully shaped by personal experience, even as he learned and meticulously applied an approach to social science research that forbade a simple translation of this experiential affect into published conclusions. He grew up in mid-twentieth century Hungary

Alexander Riley

atriley@bucknell.edu

1 Department of Sociology/Anthropology, Bucknell University, 1 Dent Drive, Lewisburg, PA 17837, USA and escaped the country as a young man after Soviet tanks rolled in to crush the 1956 democratic uprising. In his own words, these early events produced a lifelong "morbid fascination" with the processes by which some intellectuals betray their calling and come to support and aid the legitimation of totalitarianism and dictatorship.

Hollander is sometimes described as a "political sociologist," and this title accurately characterizes an important subset of his writing. He is one of the foremost American scholars of the former Soviet Union and the communist Eastern bloc, having written and edited a half dozen books that are entirely or in part directed to the study of politics, social life, and culture, and especially intellectual culture, under communism in the USSR and elsewhere in Europe. Some of his earliest writings present an acutely focused comparative analysis of Soviet and American societies and cultures. Soviet and American Society (Hollander 1973) remains one of the benchmark books of this genre. Branching across all major institutions and social structures and encompassing a consideration of how socialization and personal identity typically develop in the two societies, this study provides an effective antidote to facile attempts to understate the structural and experiential differences that informed American and Soviet beliefs and practices. The Many Faces of Socialism: Comparative Sociology and Politics (Hollander 1983) gathers together a collection of Cold War era reflections on a range of aspects of communist life in the Soviet Union, Hungary, and a few other Eastern bloc states. Highlights in this volume include careful Weberian investigations of the intricacies of communist bureaucratic life and an effort at a topic nearly entirely absent in the relevant literature, namely, a sociology of communist leisure culture and its political motivations and meanings.

A decade after the fall of communism, Hollander published Political Will and Personal Belief: The Decline and Fall of 
Soviet Communism (Hollander 1999), which is based in part on interviews with subjects living in recently post-communist societies of the early 1990s. The book's central thesis pointed to the loss of confidence in communist economy and polity on the part of elites as the most important cause of the collapse. Objective economic and political failures could be successfully spun, even ignored altogether, for lengthy periods of time, given the proper ideological commitment and rigor on the part of the societal and cultural leaders. But once the ideological faith of those elites broke, the floodgates inexorably opened. The book is an admirable testimony to intellectual honesty and humility, admitting that the causes of elite crises in confidence remain difficult to systematically summarize, as this is essentially a matter of individual conversion and change in worldview. In some of the book's subjects, one sees hints of some transformative change in the understanding of the most basic elements of the human condition, and it is clear that events in the real world have some complicated relationship to those changes. The specifics however continue to be elusive enough to make theory building on this question a problematic enterprise. Exhaustive, careful description of cases is perhaps still the best we can do, and Hollander's account of these matters excels in this exacting descriptive business.

Much of the remainder of his work touches on political sociology at various points but is more adequately understood as analysis of a particular kind of cultural response to modernity and the historical victory of democratic capitalism over collectivism (Hollander 1988; Hollander 1992; Hollander 1995; Hollander 2002; Hollander 2009). A collection of his books details the growth and spread of anti-Americanism in Western culture. Hollander uses the term "adversary culture" to describe the broad set of perspectives on which he focuses in these works. This project has taken him from detailed analysis of the institutional sources of this culture (e.g., schools, mass media, religious organizations) and the ways it has deformed those institutions to exhaustive efforts to describe and summarize the various elements of the perspective and its evolution over the period since the fall of communism.

\section{Studying Sapiens: Hollander's Sociology of Intellectuals}

Connected to this second body of work but distinguished from it by a more acute focus and broader theoretical implications are several books that together constitute a major contribution to the sociological study of ideas and intellectuals. Hollander's most recent book, From Benito Mussolini to Hugo Chavez, is the latest installment in this ongoing research effort; two previous books, The End of Commitment (Hollander 2006) and Political Pilgrims (Hollander 1981), are earlier markers of his progress in this field.
The End of Commitment is an examination of communist intellectuals who abandoned communism in the wake of the fall of the Soviet Union. Many of those described in the book were defectors who had lived in communist societies and so experienced the collapse from within. The process by which Western communists outside the Eastern bloc lost their faith was rather more complex, and Hollander provides insightful accounts of the fascinating personal trajectories some of these individuals took out of their former belief system. Understanding those who recognized the evident empirical failures of their utopian fantasies is a more straightforward, or in any event a less intriguing, task than the comprehension of those who, despite that compelling evidence, persisted in the faith. Indeed, even in this book dedicated to those who changed their minds, a chapter near the end of the book explores a number of adversary intellectuals who resisted alteration of their views. It is to this group, the substantial subset of Western intellectuals who participate in the adversary culture by identifying politically with and giving moral approbation to anti-democratic and totalitarian regimes and by critically attacking their own democratic societies, that Hollander attends in his other two major studies of the structure of alienated intellectual identity and belief. Those two books, the bookends of a now 40-year effort to explore these questions, are the focus of the remainder of this essay.

Sociologically speaking, any inquiry into the beliefs and behaviors of the intellectual class should start with a discussion of their typical social position and trajectory. Intellectuals are disproportionately drawn from the relatively privileged classes, although in democratic societies, significant numbers, though still almost certainly a small fraction, are drawn via meritocratic testing and educational processes from the talented minority of the lower socioeconomic strata as well. It is perhaps the fact of their dominant social strata of origin that makes the strongest contribution to explaining the intense alienation that a significant portion of the intellectual class experiences in capitalist democracies. The market forces that produce the reward structure of the institutions and organizations into which intellectuals are drawn for productive labor and careers determine that, while they are comparatively handsomely compensated and occupy positions of relatively high social status, there will nonetheless be social strata above them. The members of these strata have much less of what Pierre Bourdieu called the cultural capital accruing to long years in educational institutions, yet they rank well above the intellectuals in status, economic resources, and political power. This provides the material basis for Nietzschean ressentiment, a nagging and powerful sense that the condition of the intellectuals is somehow unjust, that as a class they have been victimized by some morally impure enemy that must be relentlessly denigrated and despised. 
The material base of their condition alone is however insufficient to produce the depths of alienation that Hollander describes in the core of his oeuvre. They are also marked by a lack at the level of ideas or the spiritual. They have experienced a collapse of meaningful worldviews under the pressures of democratization, the growth in technocratic power and purview, and the waning ability of traditional cultural narratives and myths to provide emotional sustenance and stability to the human psyche. Scholars of religion in modernity have lately evinced skepticism at the notion of an unstoppable wave of secularization, based on evidence not only from the parts of the world under the greatest influence of the most rapidly expanding major faith, Islam, but also from the West. It is nevertheless undeniably the case that secularization has been a serious force, largely unopposed by any major new developments in nomos building and maintenance, especially for the subgroup of humans known as intellectuals.

Institutionally speaking, intellectuals of the past were immersed in colleges and schools profoundly rooted in the Christian churches and their religious worldviews. The courses of study and the disciplinary designations in which they trained and worked were thoroughly saturated in those Christian myths and beliefs. Intellectuals are genealogically related to the priestly class, and for more than a century now analysts have pondered the transformation in their attitudes and functions since they separated themselves formally from the church. As the separation from religious values became more complete, some strata of the intellectual classes became hyper-specialized scientific technocrats, while others remained attached to the values of the generalist and evinced hostility to the growth of specialization and hard science expertise. It was this latter group that frequently replaced the old religious values that had culturally and politically anchored the clerical class with an alienated rejection of the necessarily imperfect societies they inhabited and a yearning for a more perfect State in which humanity's failings could be burned away by the moral precision of a fanatically rationalist attachment to justice and order.

When scientific and technological expertise began to push religion out of some of the institutions it had formerly dominated, significant segments of the broader population recognized and accepted the retreat of faith from the public sphere but nonetheless had no difficulty maintaining their private religiosity. Most saw no insuperable dilemma in what some intellectuals perceived as the contradiction of accepting the truths of materialist science and yet maintaining a lived connection to a traditional faith. In this sense, Walt Whitman's line about merely apparent contradiction and the multitudes an individual bears within him resonates less profoundly with those most likely to have read him, and it is those who are likely to be unacquainted with the poet who hold to his poetic truth. The intellectuals, typically rather more concerned than the average individual with the value of an unnecessary and perhaps foolish consistency, were left with a pressing need that they could respond to in one of two ways. They could work toward a mutual existence of traditional religious faith and professional commitment to secular values and truths, i.e., a version of the everyman solution so thoroughly unpalatable to many thinkers, or they could plug in some new overarching meaning system in place of the traditional one.

Hollander brilliantly describes how a subsection of these alienated intellectuals filled this gap with adherence to a set of radical political beliefs, a veneration of the thinkers and political leaders who elaborated and embodied those beliefs, and a utopian longing for the social orders to be produced by those beliefs, perfect societies that somehow could never be found to exist in reality but could yet be presumed to exist in germinal form in this, that, or another emerging totalitarian state. This group shared with another group of newly emergent intellectuals the desire for order and meaning and the refusal to look to religion for the satisfaction of the desire. Unlike this other group, though, the adversary intellectuals also tended to reject the fullest conclusions of scientific materialism that were set in motion with Darwin and eventually constituted an understanding of humankind that placed us fully in the animal world and in the long, brutal, stunning story of the evolution of life on the planet. These irreligious but yet incompletely materialist and scientific intellectuals looked instead to the realm of politics and morality to construct their new Gods and their new religion.

There exists a considerable literature on communist totalitarianism as a secular or civil religion. Here, the Lenins, Stalins, Maos, and Castros take the place of Jesus, Allah, and the saints, the cross and the crescent moon are replaced with the hammer and sickle, the storming of the Winter Palace and the Long March become the new holy dates on new religious calendars, and the selfless values of the communist man and woman replace the Ten Commandments and the words of the Prophet. Hollander's work has a distinguished place in this literature, as it vividly illustrates the lived experience of this new religion in an influential subset of the faithful, the Western intellectual sympathizers.

Utopianism is at the root of this worldview. This consists of a belief in the possibility of achieving perfect harmony between otherwise competing values, ends, individuals and groups. Any concrete observation of the world, and indeed the very etymology of the term itself, reveals utopianism as demonstrably incompatible with reality, antithetical in the most elemental way to the realm in which we find ourselves, which is thoroughly saturated in conflicts of interest that are sometimes irreconcilable in the last instance except through the imposition and exercise of power. The most parsimonious, adequate theories of human morality take this into account and accept as given that no two individuals can possibly have identical interests and that therefore only temporary and tenuous compromise is ever possible. The evolutionary biologist 
Richard Alexander and others working in this tradition are able from this starting point to explain all manner of behaviors and institutions that appear, in our quotidian language of selflessness, to be evidence of how harmony can be achieved as in fact merely ephemeral truces in inextinguishable wars and lower-intensity struggles. The utopians refuse these theoretical offerings, rich as they are in explanatory power, as the religious penitent turns from what he conceives as sin. They posit instead a world in which all conflicts of interest are driven solely by misunderstanding, corrupt structures, and evil elites. All this is to be undone by the totalitarian moralizing leader and government, and so these figures and their regimes are praised as religious saviors and heavens on earth.

The utopians take on board a whole set of pre-rational beliefs about human nature beyond their faith in the intrinsically non-conflictual root of human relations. A belief in the essentially unlimited potential of every single human, and of the species as a whole, is a potent element in the faith. Whatever seems rotten in our nature is a result of bad socialization, structures, and cultures. As orthodox Blank Slaters and Noble Savage idolaters, the adversary intellectuals refuse any hard limits to human rationality, capacity for pacific interaction, and anti-hierarchical commitment to equality. If we seem to pursue advantage, power, status, and control of others, this is simply because the right leaders and the right governments have not yet emerged. No amount of empirical evidence to the contrary can dissuade the staunchest adherents to this faith. When one dictator or regime is too clearly revealed by events as faulty, one simply moves on to the Next Best Thing: from Stalin to Mao to Castro to Daniel Ortega to Hugo Chavez, in chronological order. The will to know contributes only a fraction of the makeup of the Western intellectual psyche. The will to believe, to credulously set aside criticism and accept dogmas based on prior commitments to moral utopias, is at least as important, and in the adversary culture it becomes the engine that drives everything else.

This fantasy of the resolution of all conflicts through simple mutual understanding is rooted in a fundamentally flawed theory of human nature and the possibilities of social order. Citing Durkheim, Hollander recognizes that the social order cannot be rooted fully in a rational ground, and political projects that start from this false presumption are bound to disappointment, if not catastrophe. The revolutionary intellectuals faced this disappointment during the first wave of Western attraction to communist regimes, which took place in the several decades after the Bolshevik Revolution through the end of World War II. Hollander classifies the intellectual religion of this period as a utopianism of reason, in which it was believed that the systematic application of rationality to all aspects of human life necessarily produces a perfectly ordered and just society. This is the Enlightenment position on steroids, communist totalitarianism seen as the logical extension of the rationalizing of the human world that had, as per Marx, first produced the bourgeois West prior to inevitably producing the conditions of its demolition. But though professedly rational, this perspective is usefully categorized as religious insofar as its commitment to critical reason was so transparently limited to the rhetorical in so many details. This perspective could be found in the hyper-Enlightenment aspects of Marx's thought and it was amply present in the pronouncements and platform of the early Bolsheviks.

Downplayed in this view was Marx's other, Romantic side, and this aspect of the communist utopian religion would become the engine for later generations of Western adversary intellectuals in the wake of the obvious failure of the Soviet regime to accomplish its planned rational utopia. Beginning in the 1960 s, and consonant with a broader cultural shift to champion the power of emotion and feeling over reason, a second kind of intellectual religiosity emerged, focused on the utopianism of the passional imagination. Here, reason is seen as leading to the sclerotic decay of bureaucracy and the crushing of the deepest human strivings for experience, vitality, and authenticity. Conveniently, new totalitarian regimes that produce new leaders who depart from the stoic, stern personal blueprint of the earlier heroes (Lenin, Stalin) and instead dance, write poetry, and heartily chant slogans with the masses (Castro is the ideal type here) have emerged for the cult's attentions.

Hollander argues that this historical shift in the basic framework of utopian criticism is present in an ongoing tension in the adversary intellectual culture between two sets of competing values and sources of alienation. The adversary intellectual is desirous both of a more rational order and a more emotionally-fulfilling experience of life, drawing from the extreme offshoots of the French Enlightenment and the Romantic Counter-Enlightenment at once. It is not finally the Enlightenment that serves as the most salient inspiration for these thinkers, but rather a much earlier model of polity and its relationship to intellectuals, that of the Platonic total State and the philosopher-kings who rule it. There is also an unresolved tension in the adversary culture between the basic commitment to egalitarianism and an admiration for exceptional, elite individuals and leaders, and even a deep lack of resolution on the question of whether the individual is to be celebrated in her/his own terms or only insofar as s/he takes part in a superior collectivity.

One can see a coherent if sometimes only implicit referencing of Max Weber throughout Hollander's analysis of the predicament of the adversary intellectuals. The collapse of traditional structures of meaning in modernity has left intellectuals especially with a "painful awareness of the inability of Western pluralistic, capitalist societies to deliver sustaining values and beliefs that would enable them to confront and weather the endemic crises and frustrations of life" (Hollander 2017:294). Adherence to a variety of what Jeffrey Herf called reactionary modernism, embracing and 
criticizing modernization at once, thus becomes a common ideological tool of the intellectuals to combat this problem. It bears repeating that what is happening in the adversary culture's proposals regarding solutions to disruptions in the external world is actually also, and perhaps more essentially, a response by those intellectuals to their own inner disorder and their social position of relative deprivation.

That secular leftist intellectuals who frequently exude hostility to traditional religion are engaged through their political commitments to totalitarianism in a value and ritual system substantively indistinguishable from religion is one of the more profound insights in the recent sociology of intellectuals. How does Hollander demonstrate that this is what these adversary intellectuals are doing? The answer is in the details of how these intellectuals understood Soviet society, Communist Chinese society, Communist Cuban society, and other totalitarian polities, as well as in their vision of the leaders of these societies. Political Pilgrims and From Benito Mussolini to Hugo Chavez neatly divide up the labor: the earlier book offers a detailed account of the former, while the recent book is dedicated to a careful depiction of the latter.

\section{The Religious Pilgrimage to Political Utopia and the Adversary Intellectual}

Even now, nearly forty years after its appearance, and in the wake of the publication of reams of additional information on the scale of Western intellectual delusion on the matter of global communism, the sheer volume of the data presented in Political Pilgrims on Western intellectual affiliation with totalitarianism has the capacity to stun the reader. The capacity of individuals who were demonstrably intelligent, perspicacious, and reflective in other facets of their lives to be so gullibly taken in by the most transparent of mendacities and obfuscations is here on full, startling display. The narrative of this classic study, and of the subsequent updatings Hollander provided to include worship of new totalitarian regimes that took the place of those that had suffered a fall from grace (e.g., Nicaragua for Cuba in the 1980s), is depressingly repetitive. From the moment the adversary intellectuals arrive to visit a totalitarian communist state, they perceive the native people, or rather the tiny, unrepresentative minority of them with whom they are permitted to interact, in the Romantic terms of their political mythology. These citizens of their brave new world are endlessly praised as heroic, open, innocent, strong, brave, hospitable, enthusiastic, simple yet possessed of profound wisdom, materially poor but happily committed to something greater than mere riches, mysterious and exotic, evincing no evidence of the pettiness or self-interested narrowness of the hated Western bourgeoisie. They are Rousseau's perfect Noble Savages, existing happily outside of the pollution of the West, pristine in their austerity and authenticity.

The sites the pilgrims tour are perceived as models of organization and humanity, whether schools, factories, or prisons. Indeed, prisons in the communist world are so successful that inmates willingly stay on after their sentences are completed, and those not yet locked up flock to enter. The shrines of the revolutions and the dictators are ritually visited and celebrated in a language that can only fairly be referred to as obsequiously delusional. In one example, the Dean of Canterbury pens a stupefying letter to Stalin describing in the most overwrought terms his "bareheaded" visit to the tomb of the latter's mother, responding to the dictator's own efforts to bring some humility to the discussion of his mother's character by insisting on her perfect condition as the communist Madonna responsible for bringing the beloved Soviet Messiah into the world.

A fundamental lesson of all rigorous science is that a single observation cannot by itself be trusted as the basis of a generalization, but Hollander shows one Western intellectual after another engaging in precisely this anti-scientific variety of reasoning in evaluating conditions in one or another communist dictatorship based on their own experiences. John Kenneth Galbraith sees a single kitchen in China stocked with comestibles and infers that there cannot be a food shortage in the country. George Bernard Shaw and Simone de Beauvoir are greeted at their entry into the Soviet Union by purportedly random menial laborers who just happen to be intimately familiar with their books and the literary traditions of their countries. It never occurs to them that these random encounters and experiences might have been arranged down to the most minute detail by their hosts. Hollander details example after example of how communist host countries exploited the Western intellectual pilgrims' desire to believe in the best case scenario of their utopian tourist destinations with a combination of constant ego massage, luxurious lodging and dining, and highly selective and carefully planned itineraries that eliminated all possibility of meeting people or seeing sites not properly vetted for the visit.

An excellent comparative perspective on the intellectual tourist/pilgrim experience and reality is provided in Hollander's summary of the experience of one Andrew Smith. He saw Soviet Russia first in 1929 as a curious and sympathetic outsider courted by the regime and then again just three years later when he returned to work and live permanently there in the service of the communist revolution. In the first visit, all is in sparkling good order, the food is plentiful, the bed is soft, clothing is pressed and mended, shoes are shined, gifts are given from all quarters, reliable chauffeurs are at beck and call, all who are met offer enthusiastic greetings. On the return, though, all this has vanished along with his tourist status. There is no welcoming delegation, the amply-supplied restaurants have become barren and dirty, 
formerly well-stocked cafeterias serve only watery cabbage soup, and passersby are now as indifferent to them as they are to every other element of their everyday lives not immediately tied to their survival. Smith's insights are compelling and instructive as he is one of the rare people in print who has experienced the pilgrimage from the perspective of both the pilgrim and the coached, threatened performers presented by the regime to greet them. He tells of the Soviet workers' conflict in the face of a delegation to their factory: they will have to work extra time to get the factory floor ship shape, but at least they will be allowed to eat the tourists' scraps. Curious pilgrims ask workers about their wages and the cost of their meals and their answers are doctored on the spot by party interpreters, all without the slightest suspicion on the part of the Western admirers of the communist marvels, almost all of whom are blissfully ignorant of the native language and therefore unable to fact-check at even the most rudimentary level.

The spirit of Potemkin, the ideological imperative to portray the communist state to VIPPs (Very Important Potential Propagandists) not in its empirical reality but as a kind of lived socialist realist art aiming at a purely fictitious "emergent pregnant with the promise of the future" (Hollander 1981:389), is the driving force behind these political pilgrim tourist visits. Everywhere, the pilgrims are presented with scenes reminiscent of Vladimirski's "Roses for Stalin," a ludicrously stylized painting of Stalin dressed in white, receiving a gift of roses from young children who gaze at him as Christian celebrants gaze at the baby Jesus, at once fawning, bashful, and loving. It can rightly be said that the communists were correct about at least one thing: they understood human nature, in its weaknesses and its powerful desire for selfconfirmation and attention, more accurately than their Western intellectual admirers did, and this was the key to their ability to manipulate the latter almost completely.

Hollander's findings dovetail nicely with more recent work in social psychology that demonstrates why a Humean vision of human decision-making and behavior fits the data better than models that privilege our vaunted cognitive and rational capacities. Jonathan Haidt (2012) has metaphorically characterized the human psyche as an elephant driven by a rider who exercises only very limited control over the actions of the beast he sits astride. The rider is our capacity to reason and deliberate critically, while the elephant is the much mightier and in evolutionary terms more primordial emotional seat of dispositions and actions. Much in the way of both experimental and everyday evidence indicates there is little reason to imagine that intellectuals are somehow markedly more capable of guiding their elephants than non-intellectuals, unless they can, as in properly operating scientific communities, collectively check one another's conclusions against some objective standard of rules for verification. Hollander's research shows us the almost total lack of control that even some of the most purportedly rational have over this primitive force pushing us to confirmation of things we desperately want to believe true.

That the succession of new utopias to visit and venerate seems in danger of having exhausted itself is a problem for the adversary culture, but hardly an insuperable one. As the Nicaraguan promised land failed like its predecessors to fulfill the prophecies of the adversary intellectual faith by the end of the 1980s, there was a brief vacuum in the line of succession, though the Zapatista uprising in Mexico of the mid-' 90 s briefly attracted a good deal of hopeful adversary intellectual attention. Then at the end of that decade, Hugo Chavez came to power in Venezuela, and a few years later he was joined by Evo Morales in Peru and the next prophets had been discovered. Chavez's death a few years ago, along with the complete and catastrophic recent collapse of the Venezuelan economy, has again left a void in the pantheon, but Hollander's work suggests quite strongly that the alienated Western intellectuals will locate others, whatever the sparsity and apparent weaknesses of the field of candidates. The imperatives of the system drive the production of such political deities.

\section{From Mussolini to Chavez: The Totalitarian Superman as Object of Intellectual Veneration}

Hollander's most recent book shifts from the intellectual fascination with totalitarian utopias to their admiration of the strongmen who lead them. One of the salient advances in the more recent analysis is its demonstration that intellectual idealization of dictatorial political leaders is not limited to figures on the revolutionary left. Amidst chapters on characters whose communist regimes Hollander has previously examined in their attraction for adversary intellectuals, e.g., Lenin, Stalin, Mao, and Castro, in the new book we find alienated Western intellectuals establishing the same kind of uncritical veneration for the reactionary nationalism of Mussolini and Hitler. Despite the seeming differences of ideology, the cultic techniques and narrative constructions about the heroes are similar. Mussolini and Castro are admired in the same language of charisma and hyper-masculine display. Hitler, like Stalin and Lenin, is seen as possessed of aristocratic traits and mannerisms. All are assertive, aggressive achievers who do not hesitate to combatively confront the enemies of the fragile utopian order that is being born.

It seems a contradiction that Western intellectuals typically hostile to and personally unacquainted with exaggerated male aggression and affect should show such reverence for this trait when it appears in a utopian political leader. Yet this is perhaps no more incongruous than the idealization of a certain stereotyped iconography of a tanned, muscular peasant worker among a class of pampered Western academics who have little or no experience of hard manual labor and its more unglamorous accompaniments. This is unreflective and Romantic 
idealism, pure and simple. Positing holistic Supermen as political leaders, at once philosophers and mechanics and fruit pickers and poets, i.e., men who have achieved the Marxian goal of the perfect citizen who produces great art in the morning and cleans the stables in the afternoon, is a perfectly intelligible belief system in a class experiencing severe dislocation and alienation from the modern world of specialization and compartmentalization.

It is not just any old dictator or strong man, however, who becomes the object of veneration of the adversary intellectuals. Only those with a fully developed and articulated totalitarian vision of how to perfect society down to its most minute elements tends to inspire these faithful. It is the melding of heroic personal characteristics and a moralizing worldview that can be fitted to the intellectuals' own abstract systematizing that makes the cult work. A run-of-the-mill antiideological dictator, a mere Somoza or Salazar with their messy ideologies and haphazard politics, will simply not function appropriately in the cultic machinery. Messy piecemeal responses to complex realities do not interest this kind of intellectual; only total systems and solutions are acceptable. Hollander provides innumerable examples, some more ideal typical than others, all sharing at least some crucial subset of the relevant characteristics. The model Superman political hero of the adversary intellectuals is "omniscient, omnipresent, powerful, just, kind and caring...[needed] minimal sleep; stayed in his office from early morning until late night; managed to read several hundred pages a day...[of] politics, history, science, and fiction" (Hollander 2017:159). In Mao, we find perhaps the historical example that fits most neatly to the religious parameters of the framework. His very image was an object of veneration to which the Chinese communist citizen presented himself for instruction in the morning and for confession in the evening. Mao Zedong Thought was even taken to have magical powers, including the ability to guide successful surgeries. But if the Maoist case is the clearest, each of the examples Hollander treats can be seen to fit more or less readily into the general category.

It is the personal identities of the dictators that matter, or rather the way in which the abstract qualities the intellectuals seek in a leader and in a prototypical New Man can be creatively read into the actual individuals. They must be imposing and forceful, "Redeemer[s] endowed with a glowing sense of mission," who can through their superior will impose on the listless, "stunted, fragmented and over-specialized" mass the wholeness and totality that are so desperately needed (Hollander 2017:301). The quasi-mystical category of authenticity, a watchword for the adversary intellectuals since at least the emergence of the ' 60 s counterculture, is projected on to these sacred leaders. In her 1969 Wellesley commencement speech, a youthful Hillary Clinton offered a perfect expression of this value that had already become de rigueur for progressive political figures and in many of the new academic fields produced in the cultural effervescence of that time: "We're searching for a more immediate, ecstatic and penetrating mode of living... [an escape from] the burden of inauthentic reality" (Hollander 2017:20).

One of the more telling ways in which authenticity of the sort pursued by the adversary intellectuals can be verified is through the righteous and therefore justified use of political violence. Violence in this view is morally unproblematic and even desirable so long as it is backed by the correct ideas. A commitment to those ideas is seen as the height of moral character, and therefore acting violently in consonance with them is a manifestation of the purity of the ideal in the world. This is visible in the intellectual idolatry of the dead guerilla Che Guevara, understood in the words of Jorge Castaneda as demonstrating "the wisdom of the dead...looking at the world, assuring it that one does not suffer when one dies for one's ideas" (Hollander 2017:238), as well as in the manner in which Norman Mailer cheered at the moral purity of the violence of the Vietcong in their ruthless attacks on American troops. We see echoes of this same attitude today in the demonstrations and riots at college campuses, carried out by students but frequently fueled with the intellectual gasoline provided by professors who adhere to the values Hollander describes. As protestors at UC Berkeley, Middlebury College, Claremont McKenna College, Evergreen State University, and a growing number of other examples physically prevent speakers from addressing audiences that have come to hear them, assault innocent individuals, and wantonly destroy property, intellectuals sympathetic to them categorize their violent action as mere speech, perfectly legitimate and even morally enjoined resistance to the intolerable 'hate speech' of their non-violent opponents. The Italian Marxist philosopher Antonio Negri expressed this political sacralization of authentic, morally righteous violence in the clearest possible terms: "Whenever I pull on my passapontagna [a knitted face-mask worn by terrorists] I feel the heat of the proletariat" (Hollander 2017:313). This is, in case the reader needs reminded, an individual who served thirteen years in prison for his role in acts of terrorism that included political assassinations.

As in Political Pilgrims, in this latest book Hollander gives the reader a wealth of informative quotation from intellectuals, some obscure and others world renowned, who have adhered to the cult dedicated to the totalitarians and their dreadful regimes. A multitude of European and American postmodernists and poststructuralists, Marxists and neo-Marxists, are allowed to speak in their own dumbfounding words. Slavov Zizek's characterization of the systematic murders of Stalinism as "humanist terror," Georgy Lukacs' blunt admission that even the empirical falsification of every concrete claim of Marxism would not invalidate the theory in his eyes, C. Wright Mills and Norman Mailer waxing poetic about Fidel Castro's warmth and joviality while utterly ignoring the poverty and the political prisoners of communist Cuba, 
Jean-Paul Sartre pointing to the dictator's seeming ability to dispense with sleep and read more in a day than even the most dedicated scholars as evidence of their superhuman ability to "roll back the limits of the possible" and therefore of the requirement to free them from the normal moral rules that confine the actions of mere mundane humans like ourselves: the catalog of such banal self-deception from the pens of the adversary intellectuals is lengthy and remarkable.

Hollander all but predicts what we are already seeing emerge in primordial outline: that Islamism is the next radical political ideology the adversary intellectuals will take up as the newest, truest path away from the failures of the West, bourgeois democracy, and capitalist freedom, as the more traditional Western models of totalitarian communism and fascism are tarnished by thorough inventories of their crimes. Michel Foucault pointed the way in his fawning, naive commentary on the Islamist revolution in Iran, but more recent examples proliferate daily. On campuses around the country, it was absurdly easy in the wake of the Danish Mohammed cartoon controversy, or the Charlie Hebdo murders in France, to find professors who would openly say that they felt the victims of Islamist aggression had received what they sought in their intolerable affronts to Muslims. As I write these words, a social media wrangle is taking place around the comments of radical Muslim activist Linda Sarsour in support of the need for Western Muslims to engage in 'jihad' against the American government and the subsequent support of her remarks by some American intellectuals and media pundits. How long before the appearance of book-length analyses by tenured sociologists and literary theorists professing admiration for the latest incarnation of the hysterically anti-Western worldview represented by the radicalized imams and clerics? Hollander's work suggests they are at present likely being prepared.

\section{Reconsiderations of the Role of the Alienated Intellectuals}

The mainstream view of intellectuals, present in commentators as different as Karl Mannheim and Edward Said, as "special custodians of values like reason and justice" (Hollander 2017:4) must be revised in light of the tremendous body of evidence in Hollander's work. We must regain a skeptical perspective on the structural position and experiential predilections of the intellectuals, given the propensity of a significant minority of the class to fall into the kind of distorted, dangerous thinking and practice described in these books. To be sure, they may sometimes achieve reasonableness and justice, but they are also perfectly capable of the most stunning anti-realism, and they evince an overwhelming urge to assert themselves without evidence as high priests to whom others should defer that works in concert with their base desire for status and power.

In the effort to more fully explain the limits of intellectual discernment, Hollander fruitfully invokes the evolutionary biologist Robert Trivers' groundbreaking work on self-deception as a mechanism selected by the evolutionary history of our species. Intellectuals are perhaps still more skilled than non-intellectuals at fooling themselves into believing the most patently ridiculous things precisely because of their mastery of the rhetorical and Sophistic skills of the academy. Indeed, Trivers' theory is poignantly supported by evidence in the life of the author of the theory himself. Trivers was at one and the same time a critical evolutionary analyst of human nature and a political ally and obsequious admirer of one of the most impressively skilled charlatans of the political counterculture of the 1960s, the late Huey Newton.

Hollander's body of work is directly on target in presenting several basic behavioral and personality traits at the root of the adversary culture and its intellectuals. High idealism untempered by adequate knowledge of history and human nature, wishful thinking sufficiently strong as to make it possible to overlook the gravest counterevidence, and material interests driven by a sense of relative deprivation and outrage at not being taken seriously by the leaders of capitalist democracies go a long way toward explanation of the phenomenon. In the wake of an invocation of Trivers, perhaps a still further recourse to evolutionary thinking might be in order. Joseph Lopreato, another great sociologist who is not frequently enough recognized as such due to the innovative and unorthodox nature of his work, offered a set of basic predispositions of self-enhancement and sociality that he posited as universal basic action orientations conforming to the maximization principle (Lopreato 1984). Among these basic predispositions, several are of particular utility in contributing to Hollander's explanatory task. The climbing maneuver is an inclination to seek to advance oneself in hierarchies, and coupled with the need for recognition, a deep-seated thirst not just for position and resources but also for acknowledgement by others of one's importance, it drives a fair amount of human social life. When vertical ascent in the dominance orders is blocked, when an individual cannot attain the level he believes is his merited place and the recognition he feels his just due, the kind of Nietzschean ressentiment we see in Hollander's subjects is a frequent result. A third predisposition, the need for self-purification, combines with the climbing maneuver and the need for recognition to yield an elegant explanatory vision of what drives the adversary intellectual. The fear of one's own unworthiness and of the failure of one's entire society to make the grade, the intense self-loathing at the root of this cultural worldview, coupled with the need to make good that failed character through ritualistic means (in this case, the veneration of the likes of Stalin, Mao, Castro, and their uncommonly 
brave and hardy subjects), is what produces the alienation, which accompanies and more intensely drives the sense of relative deprivation. Hollander touches at the edges of this kind of evolutionary theory, but a fuller development of its contours would provide still more strength to the argument. We may yet hope for a book-length treatment of the basic theoretical framework that Hollander sketches in these books that would further push in this fruitful direction.

In philosophical terms, Hollander's work points us toward a deep opposition in human thought: the utopian versus the tragic. As a social scientist, he does not permit himself partisan statements in defense of the tragic worldview, but the evidence from his many books constitutes its own compelling case. Indeed, the inevitable consequences of utopianism are themselves sensible in the tragic view. Mostly basically good, wellintentioned people, acting, at least sometimes, in a spirit of openness and universality, nonetheless end by providing cover and support for brutal inhumanity and horrific mass suffering because of crucial knowledge that escapes them concerning the imperfectability of human nature and society: this is the very essence of tragedy.

Yet Hollander's conclusions even on this most basic of points are careful and conservative. An unreserved, incautious anti-utopianism can itself become problematic. It may be that utopian thought is an inevitable feature of human life, which can and should be tolerated, even mined for whatever meager utility it might contain. So long as these ideas are not implemented by force, they remain a relatively harmless feature of the transitory play activity that is human thought. Some of these adversary intellectuals might be so constituted psychically that they need such myths to stave off still more dire existential crises. They will perhaps take no comfort from the upshot of this position, but it is certainly substantially fairer and more humane than the proposals they typically make for how to deal with those with whom they disagree. These individuals can perhaps be safely left to their delusional ideal games, on the essential condition that they are carefully prevented from exercising the exceptional political influence they claim, and safeguards and vigilance must be maintained against the leakage of their hopelessly misguided ideas from their seminar rooms into the halls of power. It may be that the adherence of those who oppose the adversary culture to the bedrock principle of freedom of expression, even for their antagonists, significantly handicaps them in a struggle against ideologues who make it only too clear that their own commitment to the right of their enemies to speak is rather less uncompromising. That troubling possibility notwithstanding, this unwavering stand in defense of the great good of the widest possible freedom for intellectual inquiry is yet another marker of the stature of Paul Hollander.

\section{Further Reading}

Hollander, P. 1973. Soviet and American Society.

Hollander, P. 1981. Political Pilgrims.

Hollander, P. 1983. The Many Faces of Socialism: Comparative Sociology and Politics.

Hollander, P. 1988. The Survival of the Adversary Culture.

Hollander, P. 1992. Decline and Discontent: Communism and the West Today.

Hollander, P. 1995. Anti-Americanism: Irrational and Rational.

Hollander, P. 1999. Political Will and Personal Belief: The Decline and Fall of Soviet Communism.

Hollander, P. 2002. Discontents: Postmodern and Postcommunist.

Hollander, P. 2006. The End of Commitment.

Hollander, P. 2009. The Only Superpower: Reflections on Strength, Weakness, and Anti-Americanism.

Hollander, P. 2017. From Benito Mussolini to Hugo Chavez.

Haidt, J. 2012. The Righteous Mind.

Lopreato, J. 1984. Human Nature and Biocultural Evolution.

Alexander Riley is professor of sociology at Bucknell University. He is author most recently of The Social Thought of Emile Durkheim (2014) and Angel Patriots: The Crash of United Flight 93 and the Myth of America (2015). 